\title{
AVALIAÇÃO DA CONDUTA DE PROFILAXIA ANTIRRÁBICA ADOTADA PARA PESSOAS ENVOLVIDAS EM AGRAVOS COM CÃES E GATOS NO MUNICÍPIO DE JABOTICABAL, SÃO PAULO, NO PERÍODO DE 2007 A 2010
}

(EVALUATION OF RABIES POST-EXPOSURE PROPHYLAXIS IN HUMANS INJURED BY DOGS AND CATS IN THE MUNICIPALITY OF JABOTICABAL, SÃO PAULO, FROM 2007 THROUGH 2010)

\section{F. R. FRIAS ${ }^{1 *}$, J. O. R. NUNES ${ }^{2}$, A. A. B. CARVALHO ${ }^{3}$}

Objetivando avaliar a indicação de profilaxia antirrábica humana no Município de Jaboticabal, realizou-se um estudo retrospectivo descritivo no período de 2007 a 2010, com levantamento de dados da ficha de investigação de atendimento. Também foi calculado o custo com as vacinas destinadas à profilaxia pós-exposição. Constatou-se que das 1336 pessoas agredidas por animais, 1015 foram submetidas à profilaxia com uso de vacina, num total de 1251 doses a um custo de $\mathrm{R} \$ 22.970,10$. Do total de casos notificados, 1115 foram causados por cães e gatos clinicamente sadios no momento da agressão e que assim se mantiveram durante o período de observação, a qual foi feita pela própria vítima ou pelo dono do animal. Assim, e considerando também a situação epidemiológica da raiva no Município, essas vítimas poderiam ter sido dispensadas da profilaxia; porém, apenas $221 \mathrm{o}$ foram, ou seja, 894 pessoas receberam vacina sem necessidade. Portanto, um total de 1094 doses (R $\$ 20.134,70)$ poderiam ter sido economizadas. Conclui-se que o número de profilaxias pós-exposição contra raiva é muito alto em Jaboticabal, evidenciando que na conduta não se considerou o estado do agressor e a condição de área controlada do Município. Além de que, a observação do animal não foi feita de acordo com as normas. Recomenda-se conscientização e capacitação permanentes das equipes de saúde pública quanto à doença e observação do animal agressor, e a integração dos serviços médicos e veterinários no atendimento às vitimas visando melhor avaliação do caso, para que a decisão de se instituir ou não a profilaxia pós-exposição seja feita com critério e segurança.

\footnotetext{
${ }^{1}$ Doutora em Medicina Veterinária Preventiva. Bolsista DCR CNPq/Embrapa Gado de Corte

${ }^{2}$ Pós-graduanda Unesp/Jaboticabal

${ }^{3}$ Docente Departamento de Medicina Veterinária Preventiva UNESP/Jaboticabal

*danila.frias@colaborador.embrapa.br
} 